\title{
Faktor-Faktor yang Memengaruhi Niat Konsumen untuk Membeli Produk Melalui E-Commerce
}

\section{Factors That Influence Consumer's Purchase Intention to Buy Products Through E- Commerce}

\author{
Ariansyah* \\ Program Studi Magister Manajemen, Fakultas Ekonomi dan Manajemen, IPB University, Dramaga, Bogor 16680 \\ e-mail: arian.syah@yahoo.com \\ Mukhamad Najib \\ Program Studi Magister Manajemen, Fakultas Ekonomi dan Manajemen, IPB University, Dramaga, Bogor 16680 \\ e-mail:najib@apps.ipb.ac.id \\ Jono M. Munandar \\ Program Studi Magister Manajemen, Fakultas Ekonomi dan Manajemen, IPB University, Dramaga, Bogor 16680 \\ e-mail: jonomun@gmail.com
}

\begin{abstract}
The use of e-commerce in running a business has become a trend nowadays. This is marked by many consumers conducting online transactions to run their business or order the desired product because it is easy, fast and flexible. This study aims to analyze consumer characteristics, factors that influence the intention to buy products through e-commerce, and differences in consumers when shopping at malls and e-commerce. The approach in this study uses a quantitative approach with a survey method. This research was conducted using accidental sampling techniques with respondents totaling 121 people. This study uses primary data which is done by distributing questionnaires directly to respondents totaling 121 respondents consisting of 121 respondents to e-commerce users in the Jabotabek region. Data analysis was performed using SEM using Partial Least Square (PLS) software. This study shows that most consumers are students and domiciled in Bogor and do not have jobs yet. The objective norms and attitudes toward behavior have no significant effect on buying intentions, whereas only hypotheses related to perceptions of behavior control have been shown to have a significant effect on it. This means that consumers prefer shopping at the mall compared to shopping online.
\end{abstract}

Keywords: attitude toward behaviour,e-commerce, perceived behavior control, purchase intention, subjective norm.

\begin{abstract}
ABSTRAK
Pemanfaatan e-commerce dalam menjalankan bisnis telah menjadi tren saat ini. Hal ini ditandai dengan banyak konsumen melakukan transaksi online untuk menjalankan bisnisnya atau memesan produk yang diinginkan karena mudah, cepat dan fleksibel. Penelitian ini bertujuan untuk menganalisis karakteristik konsumen, faktor-faktor yang memengaruhi niat membeli produk melalui e-commerce, dan perbedaan konsumen ketika berbelanja di mall dan e-commerce. Penelitian ini menggunakan pendekatan kuantitatif dengan metode survey menggunakan teknik pengambilan sampel aksidental dengan responden sejumlah 121 orang pengguna e-commerce di wilayah Jabotabek. Analisa data dilakukan dengan menggunakan SEM dengan bantuan software Partial Least Square (PLS). Penelitian ini menunjukkan bahwa sebagian besar konsumen berstatus mahasiswa dan berdomisili di wilayah Bogor serta belum memiliki pekerjaan. Norma subjektif dan sikap terhadap perilaku tidak berpengaruh signifikan terhadap niat membeli, sedangkan hipotesis yang berhubungan dengan persepsi kontrol perilaku yang terbukti berpengaruh signifikan terhadap niat membeli. Hal ini berarti bahwa konsumen lebih memilih berbelanja di mall dibandingkan dengan berbelanja online.
\end{abstract}

Kata Kunci: e-commerce, niat beli, norma subyektif, persepsi kontrol perilaku, sikap terhadap perilaku. 


\section{PENDAHULUAN}

E-commerce telah meningkat menjadi medium teknologi yang penting dalam melayani pelanggan, memperluas jangkauan secara geografik, peka akan tekanan yang kompetitif, dan mengurangi biaya operasional (Martin \& Matlay, 2003; Beck et al., 2005; Wymer \& Regan, 2005). Ada beberapa pengertian tentang e-commerce, antara lain yaitu menurut Laudon (1998) e-commerce ialah suatu proses yang dilakukan konsumen dalam membeli dan menjual berbagai produk secara elektronik dari perusahaan ke perusahaan lain dengan menggunakan komputer sebagai perantara transaksi bisnis yang dilakukan.

Penelitian ini dilakukan berdasarkan jumlah pengguna e-commerce yang meningkat pada saat ini sejalan dengan kemajuan teknologi internet. Variabel yang diteliti yaitu berdasarkan theory planned behavior yang terdiri atas persepsi kontrol perilaku, sikap terhadap perilakuperilaku dan norma subjektif. Penelitian serupa oleh Aljabari, et all (2012) yang menyatakan niat membeli dipengaruhi oleh variablel-variabel dalam theory planned behavior yaitu norma subjektif, persepsi kontrol perilaku dan sikap terhadap perilaku.

Perdagangan tradisional memiliki kelemahan seperti; jaraknya jauh, waktu yang dibutuhkan sangat lama, dan barang yang dinginkan terkadang sulit didapat. Jadi masalah ini merupakan salah satu faktor yang memmengaruhi konsumen beralih ke e-commerce. Pemanfaatan e-commerce dalam menjalankan bisnis telah menjadi tren pada saat ini karena lebih mudah, cepat dan fleksibel dibandingkan dengan perdagangan tradisional.

Disamping itu banyak faktor yang menarik niat konsumen untuk membeli barang melalui e-commerce, seperti promosi yang dilakukan perusahaan e-commerce, kecepatan dan menghemat waktu, transaksi pembayaran yang cepat dan dapat mencicil, dan marketing mix. Kebanyakan konsumen menggunakan e-commerce untuk berbelanja produk makanan, elektronik, transportasi (seperti gojek/grab/uber, travel) dan lain-lain. Alasan mereka menggunakan produk e-commerce adalah penggunaannya praktis karena rincian biaya dan lokasi jelas, biaya pengantarannya gratis, pilihan produk yang beragam, dan produk bisa dibayar dengan mencicil. Oleh karena itu, banyak konsumen beralih ke e-commerce dan banyak faktor yang memengaruhi niat konsumen untuk membeli produk melalui e-commerce.

Kesadaran masyarakat Indonesia akan e-commerce masih rendah, banyak masyarakat tidak mengetahui cara menggunakannya. Hal ini disebabkan oleh faktor infranstruktur internet yang rendah, fasilitas telekomunikasi yang buruk (terutama didesa-desa terpencil). Hal ini yang masih menjadi kendala minat masyarakat Indonesia untuk bertansaksi online. Pada kajian ini dapat dirumuskan masalah tentang faktor-faktor yang dihadapi konsumen ketika membeli produk di retail modern maupun supermarket, misalnya konsumen memperkirakan untuk mencapai lokasi pusat perbelanjaan dibutuhkan waktu yang lama, biaya yang cukup besar, lokasi yang jauh dan sulit diakses oleh transportasi dan produk yang dijual terkadang tidak sesuai keinginan konsumen. Oleh karena itu, konsumen beralih ke perdagangan elektronik atau e-commerce. Masalah ini dapat diselesaikan melalui kajian untuk melihat sejauh mana faktorfaktor yang memengaruhi niat konsumen dalam pembelian produk melalui e-commerce. Kajian masalah ini didasarkan pada penggunaan teori TPB (Theory planned Behavior). Tujuan Penelitian ini adalah untuk menganalisis karakteristik atau demografi konsumen, disertai dengan menguji faktor-faktor yang mempenmaruhi niat konsumen untuk membeli produk melalui $e$ commerce.

\section{METODE PENELITIAN}

Penelitian ini dilakukan dengan suatu pendekatan secara kuantitatif dengan menggunakan metode survey. Penelitian ini dilakukan diwilayah Jabotabek dan berjumlah 121 responden pengguna e-commerce. Sampel dalam kajian ini ditentukan dengan menggunakan convenience sampling atau dikenal sampel aksidental (accidental sampling). Karakteristik responden dalam 
jumlah transaksi, pengguna atm dan jumlah penggunaan internet. Pengambilan sampel didasarkan pada penggunaan metode sampling non probability atau non random sampling dimana anggota populasi sasaran memenuhi kriteria tertentu, seperti aksesibilitas yang mudah, kedekatan geografis, ketersediaan pada waktu tertentu, atau kesediaan untuk berpartisipasi termasuk untuk tujuan penelitian (Dörnyei, 2017).

Jenis data yang digunakan dalam kajian ini adalah data primer yang menggunakan kuesioner. Kuesioner itu terbagi atas dua bagian yaitu bagian pertama yaitu terdiri dari karakteristik demografik konsumen dan bagian kedua terdiri dari varibel laten, yaitu persepsi kontrol perilaku, sikap terhadap perilaku, norma subjektif dan niat membeli. Kuesioner ini diukur dengan menggunakan skala pengukuran interval yaitu skala likert 1-6 $(1=$ sangat tidak setuju, $2=$ tidak setuju, $3=$ kurang setuju $4=$ cukup setuju, $5=$ setuju, $6=$ sangat setuju). Selanjutnya, data sekunder diperoleh melalui media perantara atau secara tidak langsung yang berupa buku, catatan, bukti yang telah ada, atau arsip baik yang dipublikasikan maupun yang tidak dipublikasikan secara umum.

Analisis data dilakukan menggunakan persamaan struktural model pengukuran (SEM) dengan metode pendekatan Partial Least Square (PLS). Penggunaan PLS memungkinkan dapat dilakukan dengan pemodelan persamaan struktural karena ukuran sampel relatif kecil dan tidak membutuhkan asumsi multivariate normal (Ghozali, 2008). Analisis outer model terdiri dari validitas konvergen, validitas diskriminan, Average Variance Expected (AVE), reliabilitas komposit, dan cronbach alpha (Hair et al., 2010). Kemudian inner model yang ada pada model struktural diuji untuk melihat hubungan antar variabel konstruk laten (Ghozali, 2008). Ada beberapa pengujian dalam model struktural yaitu R square pada konstruk endogen dan estimasi untuk koefisien jalur. Nilai $r$ square adalah koefisien dari determinasi dalam konstruk endogen yang merupakan uji goodness of fit, sedangkan perkiraan untuk koefisien jalur adalah nilai koefisien dari jalur atau sejauh mana hubungan atau pengaruh laten konstruksi dilakukan dengan prosedur bootstrap.

Pada penelitian ini mengajukan tiga Hipotesis. Pertama, penentuan pengaruh norma subjektif (NS) terhadap niat membeli. Norma subjektif adalah persepsi seseorang atau asumsi dengan harapan lainnya dari perilaku tertentu atau tidak akan melakukannya, karena persepsi ini sangat subjektif. Sikap yang sama terhadap perilaku dan norma subjektif dipengaruhi oleh keyakinan.

Kedua, penentuan pengaruh persepsi kontrol perilaku (PBC) terhadap niat membeli. Menurut Andika dan Iskandarsyah (2012) sikap merupakan kecenderungan yang dipelajari untuk memberikan respon kepada obyek atau kelas obyek secara konsisten baik dalam rasa suka maupun tidak suka. Ajzen (2010) memaparkan sikap terhadap suatu perilaku merupakan suatu fungsi yang didasarkan oleh belief yang disebut sebagai behavioral beliefs, yaitu belief individu mengenai konsekuensi positif dan atau negatif yang akan diperoleh individu dari melakukan suatu perilaku (salient outcome beliefs).

Ketiga, penentuan pengaruh sikap terhadap perilaku niat membeli. Ajzen (2010) menjelaskan perceived behavioral control sebagai fungsi yang didasarkan oleh belief yang disebut sebagai control beliefs, yaitu belief individu mengenai ada atau tidak adanya faktor yang mendukung atau menghalangi individu untuk memunculkan sebuah perilaku. Secara spesifik, dalam planned behavior theory, persepsi tentang kontrol perilaku (perceived behavioral control) didefinisikan sebagai persepsi individu mengenai kemudahan atau kesulitan untuk melakukan suatu perilaku

Penelitian ini dilakukan di wilayah Bogor dan Jakarta. Lokasi pengambilan sampel dilakukan didalam dengan membagikan kuesioner secara online maupun manual terhadap pengguna e-commerce. Sistem kerangka kerja disajikan pada gambar model konseptual Gambar 1: 


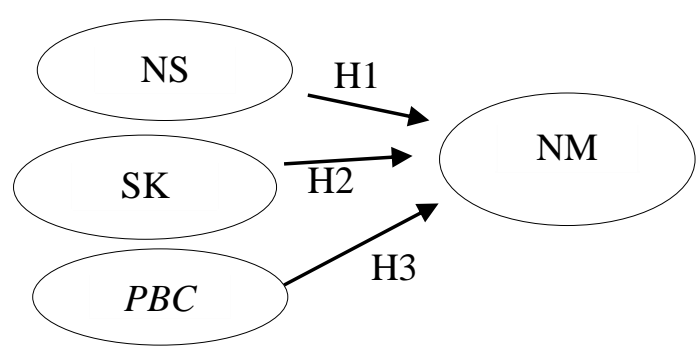

Gambar 1. Model konseptual

Berikut Laten Variabel yang diteliti yang dijelaskan pada tabel 1:

NM: Niat Membeli

NS: Norma Subjektif

SK: Sikap Terhadap Perilaku

PBC: Perceived behavior Control (Persepsi Kontrol Perilaku)

Structural Equation Modelling didefinisikan sebagai suatu teknik analisis multivariat generasi kedua yang menggabungkan antara analisis faktor dan analisis jalur. SEM memungkinkan peneliti untuk menguji dan mengestimasi secara simultan hubungan antara variabel eksogen berganda dan variabel endogen dengan banyak indikator (Latan \& Selva, 2013).

Tabel 1. Tabel variable Indikator dan Sumber

\begin{tabular}{|c|c|c|c|}
\hline Variabel laten & Definisi & Indikator & Sumber \\
\hline Niat membeli & $\begin{array}{l}\text { kecenderungan } \\
\text { konsumen untuk membeli suatu } \\
\text { merek. }\end{array}$ & $\begin{array}{l}\text { Menggunakan } e \text { - } \\
\text { commerce dimasa yang } \\
\text { akan datang. } \\
\text { Berniat menggunakan } e \text { - } \\
\text { commerce dimasa yang } \\
\text { akan datang. } \\
\text { Mempunyai rencana } \\
\text { menggunakan } e \text { - } \\
\text { commerce dimasa yang } \\
\text { akan datang. }\end{array}$ & $\begin{array}{l}\text { Lee dan } \\
\text { Ngoc, } 2010\end{array}$ \\
\hline Norma subjektif & $\begin{array}{l}\text { Norma subjektif adalah persepsi } \\
\text { seseorang atau asumsi dengan } \\
\text { harapan lainnya dari perilaku tertentu } \\
\text { atau tidak akan melakukannya }\end{array}$ & $\begin{array}{l}\text { Saran dari orang yang } \\
\text { sangat berpengaruh dalam } \\
\text { hidup. } \\
\text { Saran dari orang yang } \\
\text { paling penting dalam } \\
\text { hidup. }\end{array}$ & George, 2004 \\
\hline $\begin{array}{l}\text { Sikap terhadap } \\
\text { perilaku }\end{array}$ & $\begin{array}{l}\text { Perilaku konsumen merupakan suatu } \\
\text { proses yang berkaitan erat dengan } \\
\text { proses pembelian ketika itu } \\
\text { konsumen melakukan pencarian, } \\
\text { penelitian, dan pengevaluasian } \\
\text { produk, Perilaku konsumen } \\
\text { merupakan } \\
\text { hal-hal yang mendasari konsumen } \\
\text { untuk } \\
\text { melakukan keputusan penelitian }\end{array}$ & $\begin{array}{l}\text { Sangat baik } \\
\text { Sesuai untuk konsumen } \\
\text { menguntungkan } \\
\text { pendapat positif }\end{array}$ & $\begin{array}{l}\text { Lee dan } \\
\text { Ngoc, } 2010\end{array}$ \\
\hline
\end{tabular}




\begin{tabular}{llll}
\hline \multicolumn{1}{c}{ Variabel laten } & \multicolumn{1}{c}{ Definisi } & \multicolumn{1}{c}{ Indikator } & \multicolumn{1}{c}{ Sumber } \\
\hline Perceive & perceived behavioral control sebagai & Mempunyai kemampuan & Ranadive, \\
BehaviorControl & fungsi yang didasarkan oleh belief & membeli produk melalui & 2015 \\
& yang disebut sebagai control beliefs, & online. & \\
& yaitu belief individu mengenai ada & Dapat dikendalikan & \\
& atau tidak adanya factor yang & mempunyai pengetahuan \\
& mendukung atau & dan kemampuan untuk \\
& menghalangi individu untuk & berbelanja online. \\
& memunculkan sebuah perilaku, & Nyaman ketika berbelanja \\
& & online. \\
& & Mudah berbelanja online \\
& & dapat melakukan sendiri. \\
\hline
\end{tabular}

\section{HASIL DAN PEMBAHASAN}

Berdasarkan penelitian ini sebagian besar responden mayoritas berjenis kelamin laki-laki dengan jumlah responden sebanyak 70 orang (58 persen) dan perempuan sebesar 52 orang (42 persen). Wilayah tempat tinggal sebagian besar responden bertempat tinggal diwilayah Bogor berjumlah 36 orang (36,8 persen). Pada umumnya responden yang berusia 21-30 tahun berjumlah 93 orang (76 persen), dan diperingkat kedua yaitu responden berusia 31-40 tahun sebanyak 11 orang ( 9 persen), responden yang berusia 41-50 tahun sebanyak 9 responden ( 8 persen), responden yang berusia lebih dari 51 tahun yaitu sebanyak 3 responden ( 3 persen) dan responden yang berusia kurang dari 21 tahun yaitu sebanyak 5 responden $(4$ persen).Untuk faktor pekerjaan,responden yang bekerja sebagai pelajar dan tidak bekerja berjumlah sebanyak 48 orang (37 persen), responden yang berprofesi pekerja tetap yaitu sebesar 31 orang (25 persen), pelajar dan pekerja paruh waktu sebanyak 15 responden (13 persen), tenaga profesional sebanyak 9 responden ( 8 persen), profesi lainnya sebanyak 8 responden ( 7 persen), tidak bekerja 6 responden (5 persen), pekerja paruh waktu sebanyak 3 responden ( 3 persen) dan pensiunan sebanyak 1 responden (1 persen). Bagi sektor pendidikan, responden memiliki pendidikan sarjana atau S1 dengan total sebanyak 75 orang (62 persen), S2 sebanyak 20 responden (17 persen), S3 sebanyak 2 responden (2 persen) dan SMA sebanyak 24 orang (19 persen).

Ketika konsumen melakukan transaksi melalui e-commerce transaksi tunai yang dilakukan berjumlah kurang dari Rp250.000,00 dengan total responden sebanyak 56 orang (47 persen), responden yang melakukan transaksi sebesar Rp. 250.000,00-Rp. 500.000,00 yang berjumlah 26 responden (22 persen), Rp. 500.000,00-Rp. 700.000,00 sebanyak 23 responden (19 persen) dan lebih dari Rp. 1.000.000,00 sebanyak 14 responden (12 persen). Sebagian besar responden menggunakan kartu atm atau kartu kredit dalam melakukan transaksi online dengan jumlah responden yang menggunakan atm sebanyak 109 (90 persen) dan responden yang tidak mempunyai kartu atm atau kartu kredit sebanyak 12 orang (10 persen). Bagi waktu penggunaan internet yang dilakukan selama satu minggu, sebagian besar pengguna internet tidak menentukan waktu kapan menggunakan internet dengan jumlah responden sebanyak 80 orang (21 persen), yang bermain sebanyak 11-20 kali sebanyak 24 orang (21 persen), 1-5 kali sebanyak 4 responden (3 persen) dan 6-10 kali sebanyak 9 responden (8 persen).

Faktor yang memengaruhi konsumen untuk membeli produk melalui e-commerce adalah konsumen yang menggunakan internet untuk tujuan berkomunikasi seperti chatting dan media sosial (facebook, twitter dan lain lain) dengan jumlah responden sebesar 98 orang, diikuti oleh untuk tujuan penelitian, pekerjaan rumah dan belajar sebanyak 70 orang, untuk mencari informasi sebanyak 71 orang, berbelanja sebanyak 44 responden (12 persen), melakukan bisnis sebanyak 27 responden (7 persen), bermain gawai sebanyak 19 responden (5 persen), menonton sebanyak 38 responden (10 persen) dan untuk tujuan lain sebanyak 7 orang ( 2 persen). Ketika konsumen nal Manajemen berbelanja online, konsumen memilih berbelanja baju dengan jumlah sebanyak 79 orang, ${ }^{1}$, Organisas selanjutnya produk elektronik sebanyak 45 orang, komputer dan perangkat lunak sebanyak $28_{\text {ustus } 2020}^{1.11}$ responden (9 persen), CD dan DVD sebanyak 4 responden (1 persen), tiket bioskop sebanyak $11^{1.83-90}$ 
responden (4 persen), peralatan rumah tangga sebanyak 21 responden (7 persen) dan produk yang lain sebesar 25 responden ( 8 persen).Berdasarkan pengujian crossloading memperlihatkan seluruh variabel latennya bernilai diatas 0,5. Tahap ini juga mampu menguji pengaruh antara prediktor terhadap kriteria. Seperti contoh prediktor Norma Subjektif yang terdiri dari NS1 dan NS2 telah melewati pengujian validitas dengan nilai validitas diskriminan dengan tiap nilai crossloading diatas 0,5. Untuk prediktor PBC1, PBC2, PBC3, PBC4, PBC5 dan PBC6 bernilai diatas 0,5 ini berarti persepsi kontrol perilaku melewati tahap validitas. Dikarenakan tidak adanya masalah dengan validitas konvergen kemudian pengujian berikutnya terkait dengan validitas diskriminan. Metode ini yang dapat digunakan untuk menguji diskriminan validitas adalah dengan melihat pada tabel pemuatan silang seperti pada Tabel 2.

Tabel 2. Nilai Crossloading

\begin{tabular}{|c|c|c|c|c|}
\hline & Variabel laten 1 & Variabel laten 2 & Variabel laten 3 & Variabel laten 4 \\
\hline NM1 & & & 0,975 & \\
\hline NM2 & & & 0,972 & \\
\hline NM3 & & & 0,901 & \\
\hline NS1 & 0,953 & & & \\
\hline NS2 & 0,906 & & & \\
\hline PBC1 & & 0,962 & & \\
\hline $\mathrm{PBC} 2$ & & 0,929 & & \\
\hline PBC3 & & 0,717 & & \\
\hline PBC4 & & 0,743 & & \\
\hline $\mathrm{PBC} 5$ & & 0,843 & & \\
\hline PBC6 & & 0,946 & & \\
\hline SK1 & & & & 0,705 \\
\hline SK2 & & & & 0,8 \\
\hline SK3 & & & & 0,511 \\
\hline SK4 & & & & 0,657 \\
\hline
\end{tabular}

Tabel 2 menunjukkan bahwa nilai pembebanan setiap item konstruknya lebih besar dari nilai pemuatan silang yang bernilai di atas 0,5 , ini berarti tidak ada masalah dengan validitas diskriminan. Dari analisis pemuatan silang tampak bahwa tidak ada masalah validitas diskriminan jadi item yang tidak memenuhi nilai cross loading dihapus dari model (item awal dan uji validitasnya menggunakan validitas diskriminan dengan melihat nilai cross loading di atas 0,5 ). Analisis model luar adalah bahwa pengukuran yang digunakan layak untuk pengukuran (valid dan reliabel). Pengujian yang dilakukan pada model luar terdiri dari validitas konvergen, validitas diskriminan, rata-rata varian diekstraksi (AVE), reliabilitas komposit dan tes alpha cronbach. Pada penelitian ini, konstruksinya di atas 0,5 yang berarti valid (Hair et al., 2010)

Uji unidimensionalitas dilakukan dengan menggunakan indikator komposit dan reliabilitas cronbach alpha. Untuk kedua indikator ini titik nilai cut-off adalah 0,6 sehingga semua item pernyataan dalam tiga variabel dapat diandalkan (Hair et al., 2010). Tabel 3 menunjukkan bahwa seluruh variabelnya bernilai diatas 0,6 atau seluruh variabelnya adalah reliabel

Tabel 3. Uji Validitas

\begin{tabular}{llll}
\hline & Cronbach alpha & Composite reability & AVE \\
\hline Niat membeli & 0,945 & 0,956 & 0,902 \\
Norma subjektif & 0,847 & 0,913 & 0,865 \\
PBC & 0,928 & 0,945 & 0,743 \\
Sikap konsumen & 0,915 & 0,940 & 0,797 \\
\hline
\end{tabular}

Analisis inner model atau struktur model ketiga variable laten yang diteliti hanya satu variabel saja yang siginifikan yaitu persepsi kontrol perilaku dengan nilai estimasi koefesien regresinya terhadap koefisien jalurnya bernilai 4,889 (nilai $\mathrm{P}=0,000<0,05$ atau dengan taraf 5 persen). Namun untuk hipotesis mengenai pengaruh norma subjektif terhadap niat membeli tidak berpengaruh signifikan karena hasil estimasi koefisien regresi terhadap koefisien pathnya bernilai 0,568 ( $\mathrm{t}$ statistik $=0,57>0,05$ atau 5 persen). Sikap konsumen juga tidak berpengaruh signifikan 
terhadap niat membeli karena berdasarkan hasil koefisien regresinya terhadap nilai koefisien jalurnya sebesar 1,38 (Nilai $\mathrm{P}=0,167>0,05$ atau dengan taraf 5 persen) (Tabel 4).

Tabel 4. Uji Hipotesis

\begin{tabular}{llll}
\hline & Tstatistik & Nilai p & Hasil \\
\hline Norma Subjektif & 0,568 & 0,570 & Ditolak \\
PBC & 4,889 & 0,000 & Diterima \\
Sikap Konsumen & 1,384 & 0,167 & Ditolak \\
\hline
\end{tabular}

Berdasarkan Tabel 4, dapat disimpulkan seluruh variabel laten yaitu norma subjektif dan sikap konsumen atau $\mathrm{H} 1$ dan $\mathrm{H} 3$ tidak berpengaruh signifikan terhadap niat membeli dikarenakan nilai $\mathrm{p}$ masing-masing variabel bernilai 0,570 dan 0,167 atau bernilai diatas 0,05 , namun persepsi kontrol perilaku atau $\mathrm{H} 2$ berpengaruh signifikan terhadap niat membeli dikarenakan nilai p- nya dibawah 0,05. Temuan ini memiliki kesamaan dengan penelitian George (2014) yang menyatakan bahwa norma subjektif tidak berpengaruh signifikan terhadap niat membeli. Kang (2015) juga menyatakan bahwa sikap terhadap perilaku tidak berpengaruh signifikan terhadap niat membeli. Penelitian ini berdasarkan teori perilaku yang direncanakan yaitu terdiri atas persepsi kontrol perilaku, norma subjektif dan sikap terhadap perilaku, berdasarkan penelitian ini hanya persepsi kontrol perilaku yang berpengaruh signifikan terhadap niat membeli, hal ini kontras dengan penelitian Ketabi et al. (2014) yang menyatakan seluruh variabel laten berpengaruh signifikan terhadap niat membeli. Keseluruhan responden yang diteliti didominasi laki-laki dan bertempat tinggal di wilayah Bogor, dari keseluruhan responden yang diteliti sebagian responden memilih untuk berbelanja dimall, ini artinya konsumen lebih memilih berbelanja manual dibandingkan online. Alasannya adalah konsumen dapat melihat langsung barang yang dinginkan dan dapat menawar harga sesuai yang dinginkan.

Berdasarkan Tabel 5 nilai $\mathrm{R}$ niat membeli yatu bernilai 0,803 atau niat membeli dipengaruhi 80,3 persen oleh variabel laten lainnya seperti persepsi kontrol perilaku, sikap terhadap perilaku dan norma subjektif, sedangkan variabel niat membeli berpengaruh 19,7 persen terhadap variabel lain luar variabel yang diteliti.

Tabel 5. Uji R dan R kuadrat

\begin{tabular}{lll}
\hline Variabel laten & Nilai $\mathrm{R}$ & Nilai Rsquare \\
\hline Niat membeli & 0,803 & 0,645 \\
\hline
\end{tabular}

Berdasarkan data diatas norma subjektif tidak berpengaruh signifikan terhadap niat membeli berarti saran keluarga, teman maupun kolega tidak memengaruhi konsumen untuk membeli produk melalui e-commerce, konsumen terpengaruh untuk membeli produk melalui e-commerce melalui media cetak maupun elektronik. Untuk persepsi kontrol perilaku konsumen merasa mereka tidak dapat mengendalikan diri ketika berbelanja, belum nyaman dalam berbelanja online dan tidak mempunyai pengetahuan mengenai e-commerce. Jadi, perusahaan e-commerce sebaiknya membuat navigasi yang baik, dan mudah untuk konsumen untuk bertransaksi online, beserta petunjuk pemakaian yang mudah dan informatif.

\section{KESIMPULAN}

Karakteristik responden dalam kajian ini adalah sebahagian besar konsumen berstatus mahasiswa, atau berusia muda, dan tidak memiliki pekerjaan yang berdomisili di wilayah Bogor. Dari ketiga hipotesis yang diajukan hanya satu yang signifikan dan memberi efek positif terhadap niat beli, yaitu persepsi kontrol perilaku. Sikap konsumen dan norma subjektif, tidak memengaruhi secara signifikan terhadap niat membeli produk melalui e-commerce terutama diwilayah Jabotabek. Dalam konteks ini, konsumen lebih memilih berbelanja di Mall dibandingkan dengan berbelanja online karena konsumen dapat melihat langsung barang yang diinginkan disertai tersedianya berbagai produk, menikmati suasana nyaman, dan berekreasi bersama keluarga. 


\section{DAFTAR PUSTAKA}

Al Jabari, M., Othman, S. N., \& Nik Mat, N. K. (2012). Actual Online Shopping Behavior among Jordanian Customers. American Journal of Economics, 125-129.

Andika, M., \& Iskandarsyah, M. (2012). Analisis Pengaruh Sikap, Norma Subyektif dan Efikasi Diri terhadap Intensi Berwirausaha pada Mahasiswa Ekonomi Universitas Syiah Kuala. EcoEntreupreneurship, 190-197.

Ajzen, I. (2010). Predicting and changing behavior: The reasoned action approach. Internet Research, 14 (3), 198-212.

Beck, R., Wigand, R., \& König, W. (2005). The diffusion and efficient use of electronic commerce among small and medium-sized enterprises: an international three-industry survey. Electronic Markets, 15( 1), 38-52.

George, G. F. (2004). The theory of planned behavior and Internet purchasing. Internet Research, 14(3), 198-212.

Ghozali, I. (2008). Structural Equation Modelling Metode Alternatif dengan Partial Least Square Edisi ke-2. Semarang: Universitas Diponegoro.

Hair, et al. (2010). Multivariate Data Analysis, Seventh Edition. Pearson Prentice Hall.

Harjono. (2014). Mendayagunakan Internet. <http://harjono.dagdigdug.com/>05.

Kang, J. Y. (2015). Pendidikan dan Riset di Internet Strategi Meningkatkan Kualitas SDM dengan Riset dan Pendidikan Global Melalui Teknologi Informasi. Jakarta: Dinastindo.

Ketabi, S. N., Ranjbarian, B., \& Ansari, A. (2014). Analysis of the Effective Factors on Online Purchase Intention through Theory of Planned Behavior. International Journal of Academic Research in Business and Social Sciences, 4(4), 374-382.

Latan, H., \& Selva, T. (2013). Analisis Multivariate Teknik dan Aplikasi Menggunakan Program IBM SPSS 20.0. Bandung: ALVABETA

Lee, S. H., \& Ngoc, H. T. B. (2010). Investigating the online shopping intention of Vietnamese Student an extension of theory planned behavior. World transaction of Engineering and Technology Education, 8(4), 471-476.

Martin, L. M., \& Matlay, H. (2003). Innovative use of the Internet in established small firms: the impact of knowledge management and organisational learning in accessing new opportunities. Qualitative Market Research: An International Journal, 6(1),18-26.

Ranadive, A. (2015). An Empirical Study on the Online Grocery Shopping Intentions of Consumers in Vadodara City. International Journal of Management and Social Sciences Research (IJMSSR), 4(3).

Tung, K. Y. (2000). Pendidikan dan Riset di Internet Strategi Meningkatkan Kualitas SDM dengan Riset dan Pendidikan Global Melalui Teknologi Informasi. Jakarta: Dinastindo.

Wymer, S., \& Regan, E. (2005). Factors influencing e-commerce adoption and use by small and medium businesses. Electronic Markets, 15(4), 438-53. 